\title{
Principles of Sustainable Development in Highway Engineering
}

\author{
Jaroslav Žák ${ }^{1, *}$ \\ ${ }^{1}$ Department of Civil Engineering, Institute of Technology and Business in České Budějovice, \\ Okružní 517/10,370 01 České Budějovice, Czech Republic
}

\begin{abstract}
The objective of the proposed paper is to gain new knowledge and to verify the existing general knowledge from the area of sustainable development in the bridge and road engineering. The attention is mainly focused on mapping the localities of selected constructions before their commencement or the use of the existing information about these localities, monitoring the selected constructions during their construction and for the relevant period after they are completed. The paper will also describe creation and verification of a model of social acceptability of the construction and performance of economic assessment of the use of natural resources, potential demolition and land reclamation. The connected analyses will concern with the modification of technological procedures of construction to ensure the minimum impact on the surrounding environment.
\end{abstract}

\section{Introduction}

A building structure goes through its stages, from planning and designing, through construction, operation and maintenance to its possible removal. A complex approach to all the stages taking into account the ecological, economic and social and cultural aspects, such as safety and reliability, aesthetic criteria, functionality for the whole life time, impacts on the environment, costs of the construction, transport, maintenance but also demolition and land reclamation, is called sustainable engineering. Its products are sustainable structures.

Sustainability can also be understood as long-term compatibility. Its basic pillars are ecological, economic and social and cultural aspects. From the ecological [1-2] point of view it includes three basic protection features: protection of resources, ecosystems and human health. The solutions that only respect a part of the aspects can have negative impacts on the other ones. This results in necessity of the widest possible complex approach taking into account all the known impacts. This approach should lead to a mutually balanced compromise solution.

Data Envelopment Analysis (DEA) was used as the mathematical tool to find the above described best (or at least "very good" solution). Its theoretical background will be described in the next capture. The existing natural conditions in the territory in question must be assessed sufficiently in advance on the basis of detailed biological researches. In

\footnotetext{
*Corresponding author: zak1.j@,seznam.cz
} 
the wider context of the sustainable engineering it is especially necessary to focus on the protection of resources, ecosystems and human health.

\section{Theoretical approach DEA}

DEA models are designed as specialized model instruments for evaluating the effectiveness, efficiency, and productivity of homogeneous production units. DEA involves the use of linear programming methods to construct a non-parametric piecewise surface (or frontier) over the data, so as to be able to calculate efficiencies relative to this surface. DEA models derive from the concept that for each given problem there exists a so-called production possibility set consisting of all possible (feasible) combinations of inputs and outputs. The set of feasible possibilities is determined by the so-called efficiency limit. Production units with combinations of inputs and outputs lying on the efficiency limit are considered as efficient ("good") units.

Our solution uses the BCC model, designed in 1984 by Banker et al. [3]. This model assumes variable returns to scale; data are contained by a convex set and therefore more than one unit can be designated as efficient. The model can either maximize outputs (output-oriented) or minimize inputs (input-oriented). Similar DEA approach was used in [4], where the effectiveness of extended EU countries from economic and environmental indicators point of view was evaluated or in [5] and [6], where the good solutions for motorway underpasses were found.

A mathematical representation of the dual input-oriented BCC model is shown below. Let us assume we have units $U_{1}, \ldots, U_{n}$. Also assume we have $m$ inputs and $r$ outputs. We denote the input matrix as $\boldsymbol{X}=\left\{x_{i j}, i=1, \ldots, m, j=1, \ldots, n\right\}$ and the output matrix as $\boldsymbol{Y}=$ $\left\{y_{i j}, i=1, \ldots, r, j=1, \ldots, n\right\}$. The model for unit $\mathrm{U}_{\mathrm{q}}$ is formulated as follows, minimizing the function

$$
z=\theta_{q}-\varepsilon\left(1^{\mathrm{T}} s^{+}+1^{\mathrm{T}} s^{-}\right)
$$

where $\theta_{q}$ is the efficiency of unit $q ; x_{q}$ is the $q$ th column of the $X$ matrix; $y_{q}$ is the $q$ th column of the $\boldsymbol{Y}$ matrix; $\lambda=\left(\lambda_{1}, \ldots, \lambda_{n}\right)^{\prime} \geq 0$ is the weight vector; $s^{+}$and $s^{-}$are vectors of additional variables in limitations for inputs and outputs, $\mathbf{1}^{\mathrm{T}}=(1, \ldots, 1)$; and $\varepsilon$ is an infinitesimal constant that usually equals $10^{-8}$.

Therefore we select minimized input matrix $\mathrm{X}$ - costs $\mathrm{C}$, additional costs $\mathrm{AC}$ and maximized output matrix $\mathrm{Y}$ - technical migration potential $\mathrm{Pt}$ and ecological migration potential Pe.

The results matrix provides a large amount of information, in particular identification of "good" solutions (units). Inputs that result in the highest inefficiency and which therefore should be improved where possible are also marked.

\section{Methodology of solution}

\subsection{Ecological aspects}

Acts of the individual countries stipulate clearly which construction must be subjected to the process of the construction environment impact assessment (EIA). The use of natural materials must be assessed not only as regards the quality and price but it is also necessary to assess all the impacts on the surrounding environment, to optimise the occupation of arable soil and forests and to optimise the degree of polluting of the territory with noise emissions, harmful substances and waste. 
It is suitable to assess the condition of fauna and flora in cooperation with specialists in the individual fields of biology who know the territory in question very well (zoologists, ornithologists, entomologists and botanists from the nearest regional museums and other specialist workplaces, employees of the state nature protection, members of local hunting clubs etc.). If the original biotopes that are going to disappear as a result of the construction are permanently or temporarily connected with specially protected species of plants and animals which could be transferred to alternative localities, it is necessary to perform these rescue transfers.

On the basis of the assessment of the existing situation of the territory in question it is necessary to optimise the progress of the construction so that it would disturb the environment as little as possible and to propose measures that would bring the achievable harmonisation of the construction with the surrounding environment also after the construction is completed, including the land reclamation of the surrounding of the construction or restoring its original condition. Subsequent monitoring and assessment of the way of construction can verify the efficiency of the measures taken and correctness of the general knowledge. Monitoring of the construction and its surroundings after the use of the construction is commenced should verify to which extent the impacted territory is returning back to its original condition.

An important part of ecological aspects is proposal of special structures for protection against noise pollution and also of structures enabling maintenance of the existing possibilities of the migration of animals as means minimising fragmentation, at least in acceptable conditions. These structures include especially eco-ducts and various kinds of passages. When they are being designed, it is mainly necessary to pay great attention to their location in the terrain, best in the places of existing natural migration routes, or in the places predetermined for it in the land-use plan. The design and performance must enable their future functional use. That is why it is important to choose not only the correct shape and materials used but also adjustment of the transferred surface and places of access.

In connection with the location of the eco-duct with regard to the surrounding terrain and the line construction it is possible to divide eco-ducts into two basic types, i.e. ecoducts situated in an earth cut and eco-ducts situated in flatland, or in filling. In the cuts it is suitable to use mainly a tunnel type of eco-duct of straight ground plan. This type has preconditions to meet aesthetic aspects, it naturally fits in the landscape that was divided artificially by the line construction and it creates migration routes for a wide range of animals. Apart from the tunnel type of eco-ducts with straight ground plan, in the cuts it is also possible to use a tunnel type of eco-duct with hyperbolic ground plan. Eco-ducts of this type are not as financially demanding as a similar type with the straight ground-plan. In case of its optimum implementation, this type of eco-duct can also be used for creation of a migration route for a large range of animals. However, its disadvantage is reduced width, which is one of the important factors influencing the function of eco-ducts. On flatland arched eco-ducts are used. Their disadvantage is quite a big occupation of land in front of and behind the eco-duct, as it is necessary to transfer the eco-duct across the line construction and thus to create an artificial obstacle that does not exist in the surrounding countryside. In order not to disturb the character of the landscape it is thus necessary to choose a very small gradient of the eco-duct surface. In fillings eco-ducts are solved in a form of underpasses under the line constructions.

At the moment eco-ducts are mostly designed as reinforced concrete monolithic or prefabricated covered structures with a constant or variable thickness. In case of the central line with variable thickness, the minimum thickness of the structure in the top point and towards the supports is gradually extended. The central line of eco-ducts is mostly in a shape of an arc or vault, because with the use of frame structure the eco-duct would not fit naturally in the surrounding countryside. With regard to the possible decrease of costs of 
construction and decreasing of the ecological demands of the construction of the eco-duct from reinforced concrete it is suitable and desirable to look for materials that could replace some of the reinforced concrete components, at least partially, such as aggregate with the use of waste debris or recycled concrete. Verification of the applicability and suitability of new progressive materials is also a part of the solution.

As regards functionality, one of the decisive factors of eco-ducts is their width, i.e. the dimension of the eco-duct along the axis of the line construction. It is not possible to determine positively the optimum width of an eco-duct enabling migration of animals, as its size is directly connected with the size of the animals that will migrate through the ecoduct. In the Czech Republic, with regard to the size of large animals, among which it is possible to include roe-deer, stag, chamois etc., the standard recommended width of ecodusts is $45 \pm 5 \mathrm{~m}$, exceptionally $25 \pm 5 \mathrm{~m}$. These parameters are only applicable in places where the other factors influencing the function of the eco-duct are within the optimum values, e.g. a place with almost no disturbance, perfect vegetation finish of eco-ducts, natural connection to the adjacent landscape structures. In case the parameters of the ecoduct location are not within optimum values, it is necessary to increase the width of the ecoduct adequately to the needs. For eco-ducts interconnecting biotopes that will be used also by other than large animals, the recommended minimum width of the eco-duct is more than $50 \mathrm{~m}$.

Another crucial factor influencing functionality of eco-ducts is their surface treatment. For eco-ducts that will be mainly used for migration of animals it is necessary to perform the surface treatment in such a way so that the eco-duct is not separated from the surrounding environment, i.e. soundproofing and visual separation of the eco-duct from the line construction. For eco-ducts interconnecting divided biotopes it is suitable to imitate the character of the biotope and area by means of the surface treatment in order to make migration of all organisms possible. Planting of eco-ducts should comply with ecological aspects. The technical equipment of eco-ducts should be as minimalist as possible. On the eco-duct and it its proximity there should not be any unnatural obstacles, such as concrete obstacles, drainage canals etc. Also lighting of the line construction under the eco-duct should be solved in such a way so that not to interfere with and influence the light conditions in the eco-duct and thus not to disturb the natural migration of animals.

In connection with the use and development of eco-ducts it is also necessary to deal in more detail with the technological procedures of their construction as regards the minimum impacts on the surrounding environment in the course of the construction, or to deal with the proposal of necessary measures to minimise the impacts of the construction. At the same time it is desirable to deal with the proposed optimum shape of the supporting structure and materials used for its construction. For the design of the optimum shape of the supporting structure and materials it is suitable to use one of the computer systems based on the final element method. To determine the optimum shape of the supporting structure it is necessary to perform linear or also non-linear parametric analyses that should also take into consideration the influence of uncertainty in the input parameters arising from the fact that all the input quantities describing the structure dimensions and geometry, qualities of materials, load, impacts of the surrounding environment etc. are due to their nature random quantities or random processes. Also our incomplete knowledge of the phenomena and processes occurring in the structure, and unawareness of the statistic information concerning the input quantities are a source of uncertainty, like uncertainty arising form inaccuracy of the calculation models applied. During the solution, the calculation systems based on FEM will also be used for studying of moisture fields and influence of permeability of layers of fillings of both the existing and designed eco-ducts, as they have direct impacts on the surface treatment, i.e. vegetation on the eco-duct. On the basis of these analyses and experimental measuring it is possible to gain new general knowledge 
and regularities that can be used in optimum designs of eco-ducts, especially the thickness of filling and types of soils usable in these fillings. At the same time it is desirable to deal with the general description of the water regimen, as the basic prerequisite of successful performance of plantation on the eco-duct and in its surrounding.

\subsection{Economic aspects}

Within the complex approach to the sustainable engineering it is necessary to emphasise more the following:

- Costs of the potential removal of the construction, waste disposal, including the impacts on the environment.

- Selection of construction materials, not only as regards their strength and durability etc. but also with regard to demolition, possible recycling and problems with their disposal.

- Reduction of negative impacts of the construction on the environment in the process of the construction, during its use and also after its possible permanent removal.

- Efficient use of soil

- Biodiversity and quality of the environment where the economic and ecological aspects are directly interconnected.

Generally we can state that the economic aspects cannot be analysed separately within the scope of sustainable engineering (which naturally also applies to any other aspect). The efficiency and optimising (not minimising) of costs must be included integrally in the principles of the planning, design as well as construction. Within the scope of the solution all the activities will thus be subjected to economic calculations with the aim of their overall optimising.

\subsection{Social and cultural aspects}

Every bigger construction, such as for example a line construction (motorway, dual carriageway), is perceived in a very sensitive way by the population. Its location in the countryside is often received with significant protests of both organised and unorganised groups, often with opposing interests and opinions. To recognise the social perception of the construction already in the stage of the project planning and preparation can facilitate the engineering activities, acceptance of the construction and thus also the speed of the construction, shorten the deadline for the completion and improve the overall construction efficiency. The assessment of the social benefits and negatives can be a part of the initial documents for planning of a similar construction in future. A part of the complex approach within the sustainable construction should also be a model of social acceptability.

Like the economic aspects, the model of social acceptability cannot be assessed in any other way than in direct connection with the ecological and economic aspects. It is quite a difficult task to transfer the subjective views of the public and their often incomplete and biased information about the construction to a measurable quantity. A part of the solution is creation of a model of social acceptability of the construction. For this purpose the public is divided into three basic groups: users, losers (those who lose) and winners (those who gain). Generally, a personality of a particular person can comprise of all three groups. With means usual for the opinion poll, selected (proportionally represented) groups of the population will be addressed. For the individual respondents, the proportion of representation of the individual groups will be assessed. With regard to the fact that the input quantities are not specified unambiguously and they are a source of great uncertainty, it is necessary to use methods of stochastic analysis with many corrective functions. The positive opinions of users and winners as well as the negative opinions of the losers must be reduced in a suitable way. The result of the model is a real number within the interval from 
-1 to 1 , where the first number means total rejection of the construction and the other the total and unconditional acceptance of the construction.

\section{Conclusions}

The contemporary society is almost all the time burdened with conflicts of various interest groups and political parties concerning the appearance and location of key line constructions. It turned out that it is a highly complicated process to harmonise the interests of the individual groups, economic aspects and impacts on the environment. A complex and independent approach to the solution of this problem is thus highly topical.

The result of the solution will be gaining of new knowledge and verification of the existing general knowledge from the area of sustainable development in the bridge and road engineering. The presented methodology is based on the existing technical knowledge set inseparably in the economic, ecological and social and cultural aspects of the sustainable engineering.

\section{References}

1. A. P. Clevenger, M. P. Huijser, Wildlife Crossing Structure Handbook, Design and Evaluation in North America, (Washington D.C., USA: Federal Highway Administration, 2011)

2. A. P. Clevenger, Proceedings of the ICOET, 433-447, (2012)

3. R.D. Banker, A. Charnes, W. Cooper, Management Science, 30(9), (1984)

4. L. Issever Grochová, K. Myšková, J. Žák, 12th International Conference of Numerical Analysis and Applied Mathematics, 1623-1628, (2014)

5. K. Myšková, J. Žák, Data Envelopment Analysis for Technological, Environmental and Economic Analysis of Motorway Underpasses, Acta Mendelu Brno, 64, (2016)

6. K. Myšková, J. Žák, 11th ICNAAM 2013, 1867- 1870, (2013) 